\title{
ERRADICACIÓN EN SUSPENSO: \\ LA DIMENSIÓN SIMBÓLICA DE LA PACIFICACIÓN NEGOCIADA EN EL VRAEM
}

\author{
Putting Eradication On Hold: \\ The Symbolic Dimension of a Negotiated Pacification in the VRAEM
}

\author{
MARITZA PAREDES ${ }^{1}$
}

Pontificia Universidad Católica, Perú

\author{
ÁLVARO PASTOR \\ Pontificia Universidad Católica, Perú
}

\begin{abstract}
RESUMEN
Este artículo explica la implementación heterogénea de la erradicación de cultivos de coca en el Perú, particularmente las sucesivas suspensiones de erradicación en el VRAEM, el productor más importante. El VRAEM permite examinar la capacidad estatal y las relaciones del Estado con actores no estatales que resisten sus políticas de erradicación, particularmente los cocaleros. Concluimos que la tolerancia estatal responde a un proceso de acumulación del capital simbólico del Estado, producido en la negociación con los cocaleros. Estos actores sociales reclaman a cambio el reconocimiento de su papel y de la economía cocalera en la pacificación y el orden establecido. Este orden es híbrido, pero posibilita el desarrollo del Estado, el control de la violencia y evita el monopolio de la economía ilícita por parte de actores insurgentes.
\end{abstract}

Palabras clave: la política de la coca, la economía política de las drogas, VRAEM, capacidad estatal.

\begin{abstract}
The article explains the heterogeneous implementation of coca crop eradication in Peru, particularly the successive suspensions of eradication in the VRAEM, the most important producer. The VRAEM allows examining state capacity and state relations with non-state actors' resistance, particularly coca growers. We conclude that state tolerance responds to a process of accumulation of the State's symbolic capital, produced in negotiation with coca growers. These social actors demand in return recognition of their role and the coca economy in the pacification and the established order. This order is hybrid, but it makes possible the State's development, the control of violence, and avoids monopolizing the illicit economy by insurgent actors.
\end{abstract}

Keywords: coca politics, political economy of drugs, VRAEM, state capacity 


\section{INTRODUCCIÓN}

Desde fines de los 70s, el gobierno peruano sigue una política nacional de control de cultivos ilícitos de coca que consiste en su erradicación forzosa y la promoción de programas de desarrollo alternativo (Cotler 1999; Ponce 2016). Numerosos estudios explican la inefectividad de estas políticas de prohibición y las consecuencias negativas de la criminalización sobre los agricultores. ${ }^{1}$ Este artículo analiza un ángulo diferente de la política de control de cultivos ilícitos de coca. Se examina porque a pesar de la persistencia de la política nacional de erradicación en el Perú, su implementación es tan diferenciada a nivel subnacional entre los valles de producción, en particular en el Valle de los Ríos Apurímac, Ene y Mantaro (VRAEM). A esto le llamamos una implementación heterogénea de la política nacional de control de cultivos ilícitos de coca.

Observamos que las cifras de erradicación son muy diversas entre los cinco valles con mayor concentración de coca ilícita durante el periodo 2002-2019: el VRAEM (18500 hectáreas); el Monzón-Alto Huallaga (Monzón-AH) (10000 hectáreas); San Gabán- Inambari (2250 hectáreas); el corredor Amazónico de la Selva Central (1200 hectáreas) y La Triple Frontera, con Colombia y Brasil (1200 hectáreas. ${ }^{2}$ Desde el 2002, en el VRAEM las hectáreas erradicadas no llegan al uno por ciento de la extensión cultivada. ${ }^{3}$ En cambio, en Monzón-AH y en La Triple Frontera se erradicó en ambos más de la mitad de la producción cultivada (64 y 56\%, respectivamente) en el mismo periodo. La situación del VRAEM es atípica, dado que es el primer productor nacional indiscutible desde el 2010 con el 71\% de la producción nacional de hoja de coca en el 2019. ${ }^{4}$ Sin embargo, la erradicación ha sido prácticamente inexistente: 116.17 hectáreas en el 2019, menos del $0.5 \%$ de su producción. ${ }^{5}$ Los contrastes, en particular con el Monzón-AH, son significativos. En lo que sigue del artículo haremos fundamentalmente referencia a estos dos valles por la mayor extensión de cultivos y su relevancia histórica.

Además no existen condiciones especiales que nos hagan esperar estos resultados tan diferentes entre el VRAEM y el Monzón-AH; como un conflicto armado activo o una geografía mucho más compleja. ${ }^{6}$ En ambos valles cocaleros, la capacidad coercitiva y administrativa del Estado, dimensiones fundamentales de la capacidad estatal (Soifer 2012), son bastante similares. La presencia militar-policial es similar; con un total de 10 comisarías en cada valle (INEI

\footnotetext{
Ver Youngers y Rosin 2005; Keefer y Loayza 2010; Buxton 2015; Dávalos 2016.

Promedio anual de cultivo para el periodo 2000-2017, UNODC $(2002 ; 2014 ; 2018)$

La información de los años 2014 - 2019 está disponible en CORAH (S.F). Los datos de cultivos ilícitos son obtenidos de (UNODC 2002; 2014; 2018) La información para años anteriores fue proporcionada en una entrevista a un ex funcionario del CORAH (periodo del 2000 - 2013).

DEVIDA (S.F).

CORAH (S.F).

Si existe alguna forma de colusión entre miembros de la policía y /o militares y actores narcotraficantes para el tráfico ilícito esto ocurre en ambos casos. Por lo cual, este factor no ayuda a entender la heterogeneidad de la implementación de la política de erradicación.
} 
2017), y equipos especializados antidrogas y antisubversivos que combinaban fuerzas policiales y militares, tales como el Comando Especial VRAEM y las Bases Antinarcóticos en el Monzón-AH. ${ }^{7}$ La presencia estatal administrativa, medida a través del Índice de Densidad Estatal (IDE) producido por el PNUD, ${ }^{8}$ muestra que, en el 2017, el IDE en las provincias del VRAEM es cerca de 0.7 y en las provincias del Monzón-AH mantiene niveles de 0.6. En casi todas las provincias tanto del VRAEM, como en el del Monzón-AH, el IDE se incrementó en promedio en 20 puntos porcentuales entre 2007 y 2017. Adicionalmente, en ambos valles se ha incrementado el presupuesto público per cápita, siendo el presupuesto del VRAEM casi el doble del Monzón-AH en el 2019, \$US 478 y US $\$ 242$, respectivamente. ${ }^{9}$

La constatación de una política de tolerancia en el VRAEM nos invita a preguntarnos en qué contextos y con qué recursos los actores sociales tienen la oportunidad de negociar o no el alcance de las políticas de control del Estado respecto a las economías ilegales con las cuales se vinculan; por qué en algunos casos, como en el Monzón-AH, los cultivos son erradicados y sus agricultores criminalizados, y en otros casos, como en el VRAEM, no. El análisis subnacional, nos permite profundizar en el rol que tienen actores, instituciones y prácticas locales que a menudo son no visibles cuando estas políticas son analizadas exclusivamente desde teorías y metodologías de nivel nacional (Giraudy et al. 2019).

El argumento del artículo sobre la política de tolerancia en el VRAEM plantea que la capacidad de los actores sociales, de la organización de agricultores cocaleros, de negociar la implementación de políticas nacionales como la suspensión de la erradicación en sus territorios responde al poder de la reivindicación de las alianzas que se establecieron entre estos actores y el Estado, en particular las fuerzas militares, en el pasado, para luchar contra la subversión, lograr el control del Estado del territorio y construir una legitimidad local de la presencia estatal. En cada intento de erradicación, los actores sociales han reivindicado esta alianza forjada en el pasado. Las sucesivas suspensiones de la erradicación en el VRAEM expresan el temor de los gobiernos de socavar esta legitimidad estatal local, que se ve amenazada cuando se intenta llevar adelante la política nacional.

Este argumento empírico contribuye a pensar la capacidad estatal teóricamente en dos aspectos. Primero, la capacidad estatal es relacional (Giraudy y Luna 2017); es decir la expansión del alcance territorial del Estado requiere la nego-

El Comando Especial VRAEM es liderado por el Ejército, con apoyo de la Policía Nacional del Perú. En el Monzón lidera la Policía Nacional estando las principales bases en Santa Lucía y Tingo María.

$8 \quad$ Este índice mide la presencia territorial del Estado usando indicadores de nivel provincial tales como: i) número de médicos por cada 10,000 habitantes; ii) tasa de asistencia escolar secundaria; iii) porcentaje de viviendas con agua y desagüe; iv) porcentaje de viviendas con electricidad; y v) porcentaje de la población con documento de identidad (PNUD 2019: 84-87).

9 Datos disponibles de presupuesto público en Consulta Amigable del MEF (S.F) y datos poblacionales en INEI (2020). 
ciación con actores no estatales. Lo que podría entenderse como falta de capacidad estatal en el VRAEM, la suspensión de la erradicación, más bien expresa las formas complejas en las que los Estados negocian su presencia y construyen capacidades políticas (Mann 1986) para configurar un orden local. Como en el VRAEM, este orden puede ser de un equilibrio frágil por convivir con la ilegalidad (Heuser 2019), pero como en otros casos estudiados de este tipo, este orden puede ser funcional para sus actores, incluidos los actores estatales (Dewey 2018, 2015). En el caso del VRAEM, por un lado, responde a las demandas de los agricultores de tolerar los cultivos ilícitos; y, por otro lado, controla la violencia que se ha desatado en otros territorios de ilegalidad (Duran-Martinez 2015, Trejo y Ley 2020) y permite el continuo desarrollo del Estado en una zona de alta actividad ilícita. Esta capacidad de construir una presencia estatal negociada es para Mann (1986) un "meta-poder" porque tiene por consecuencia la aceptación de la presencia y la centralización del poder del Estado, que de otra forma (ej. militar) sólo ocurre de una manera muy precaria y a un alto costo (Mann 1986: 521).

Segundo, la literatura de los órdenes híbridos se ha concentrado en la negociación con actores ilegales, e incluso armados (Mehan 2015; Dewey 2016; Auyero y Sobering 2019). Este artículo contribuye en destacar el rol y la importancia de los actores sociales, como los agricultores cocaleros, que se vinculan directa o indirectamente a las economías ilícitas, y se diferencian de los actores criminales narcotraficantes o armados en sus territorios. Los actores sociales además revelan la dimensión simbólica de la capacidad política de negociación a la cual se refiere Mann (1986). Bourdieu (2014) sostiene que la construcción del Estado en el territorio se hace sobre la base tanto de capitales materiales (como el militar o administrativo) como no materiales, simbólicos. ${ }^{10}$ Bourdieu (2014) al resaltar la dimensión simbólica de esta capacidad política del Estado de la que habla Mann (1986), enfatiza en la importancia de las nociones de significado compartidos respecto al poder en el territorio. La construcción de la legitimidad de un orden estatal en el VRAEM, a pesar de la ilegalidad, se inicia con la colaboración de los agricultores cocaleros a las fuerzas armadas en la lucha antisubversiva, y continua con el proceso sostenido de pacificación en el territorio. Esta colaboración en la práctica constituye la dimensión simbólica de la capacidad estatal en el VRAEM, la rutinización de su presencia y lo que se "entiende y espera" del Estado cotidianamente (Bourdieu 2000).

Metodológicamente, el VRAEM es analizado como un caso atípico que nos permite contribuir con explicaciones matizadas (Rogowski 2010) sobre la capacidad estatal en territorios de actividad ilícita. Recogemos los datos etno-

10 Viniendo de tradiciones muy diferentes, existe un creciente reconocimiento de la utilidad y convergencia de ambos autores en su concepción del poder del Estado (Janosky 2019). Ambos plantean que el poder estatal sobrepasa las nociones de coerción que incluyen factores materiales como el dinero, los recursos y la fuerza. Los conceptos de poder político y simbólico de Mann y Bourdieu, respectivamente, enfatizan en la importancia de los supuestos, las ideas y los significados compartidos respecto al poder (Mann 1986, Bourdieu 2014). 
gráficamente en un campo que se inició a mediados del 2019 como parte de un proyecto aún en curso. ${ }^{11}$ Este artículo usa parte de los datos recogidos en dos campos extensos entre diciembre del 2019 y febrero del 2020. Usamos también otros datos de fuera del VRAEM, ya que estudiamos el VRAEM en un "contexto amplio", internacional y nacional, para analizar "sus variaciones, resistencias, oportunidades y adaptaciones" en las múltiples formas en las que el capitalismo global y los Estados nacionales interactúan con estos territorios (Lapegna 2019: 11).

El artículo está organizado en seis partes. La segunda sección presenta la discusión teórica del artículo. La tercera sección describe los tres intentos fracasados de erradicación en el VRAEM. La cuarta sección presenta el origen histórico del poder simbólico de la pacificación y la política de la tolerancia. La quinta presenta cómo se vive en lo cotidiano esta apelación al Estado cuando hay amenaza de erradicación. Finalmente, la sexta sección presenta las conclusiones.

\section{ACTORES SOCIALES, NEGOCIACIÓN DEL PODER ESTATAL Y SU DIMENSIÓN SIMBÓLICA EN CONTEXTOS DE ILEGALIDAD}

La literatura sobre drogas ha tendido a explicar la variación entre países productores respecto a la inefectividad de estas políticas en la reducción de cultivos ilícitos a nivel global (Keefer y Loayza 2010; Buxton 2015) y la debilidad de los Estados centrales en aplicar la ley en contextos geográficos complejos y violentos (Thoumi 2010; Rosen y Kassab 2019). Asimismo, destacan que el contexto de altos precios internacionales socava los esfuerzos de las políticas estatales, ya que el cultivo se desplaza de un lugar erradicado a otro, generando el efecto "globo" (Arce y Reales 2006; Rouse y Arce 2006). Sin embargo, esta literatura ha prestado menor atención a la variación subnacional de estas políticas.

La literatura de la política subnacional, en contraste, muestra la heterogénea acción de los Estados nacionales en su territorio en múltiples dimensiones (Giraudy et al. 2019); en el cumplimiento de la ley, en la distribución de servicios públicos, en el manejo del conflicto social, entre otros. Además, estos estudios destacan el carácter relacional de la capacidad estatal. No basta con examinar los malos diseños de política, recursos insuficientes o funcionarios incapaces (Migdal 2001: 12). Los Estados se relacionan y enfrentan también a actores locales que les imponen resistencia (Boone 2012; Eaton 2012; Dargent et al. 2017).

En el análisis de la ilegalidad, estos estudios resaltan que la relación entre actores estatales y actores no estatales armados no es binaria. Es decir, no asumen que el Estado es el ente encargado de regular las actividades ilegales y generar orden social, y que los actores no estatales desafían la aplicación de la ley 
y generan desorden. Varios autores explican cómo el Estado es más bien un "conjunto polivalente y polimorfo" donde varios "proyectos estatales" compiten entre sí (Auyero y Sobering 2019: 12), varias veces, infringiendo su propia legalidad y creando formas de tolerancia negociada a las economías ilícitas (Dewey 2016). Este enfoque relacional además ha permitido explicar porque hay espacios ilegales más violentos que otros. Las diversas formas de relación entre actores armados locales y actores estatales sirven para entender la configuración de órdenes locales y sus diferentes formas y grados de violencia. Esto se ha estudiado en territorios urbanos (Duran-Martinez 2015; Arias 2017; Auyero y Sobering 2019; Moriconi y Peris 2019; Trejo y Ley 2020) como en zonas rurales de producción de cultivos de coca (Ballvé 2012) y opio (Meehan 2015; Mansfield 2016).

Para nosotros, estas investigaciones aportan los cimientos del análisis de las relaciones de poder entre el Estado y actores no estatales. Sin embargo, al estudiar zonas con altos niveles de violencia donde prevalecen actores armados poderosos y políticamente conectados - como las pandillas, cárteles de drogas y grupos paramilitares - la sociedad civil es vista principalmente como una víctima potencial del nexo entre el Estado y el crimen (Trejo y Ley 2020: 62); cuya acción cívica e interacción con el Estado es limitada y amenazada por estos actores armados no estatales, incluso cuando estos son desorganizados (Arias 2017). Tal como señala Arjona (2017) dicho énfasis en la relación actor estatal actor criminal poderoso ha silenciado las diferentes formas de respuestas (de cooperación o no cooperación) de los actores civiles en contextos de economías ilícitas y guerras civiles, así como su rol en la configuración de estos órdenes sociales subnacionales.

Este artículo argumenta que los actores civiles, en particular, las organizaciones sociales, pueden jugar un rol importante en la heterogénea acción subnacional de los Estados en contextos de ilegalidad. En la literatura de cultivos ilícitos, los actores sociales han sido estudiados principalmente como movimientos sociales nacionales que se oponen a los intentos de erradicación (Ramírez 2001; Durand-Ochoa 2014; Grisaffi 2019). Sin embargo, menos atención se le ha dado a nivel subnacional, cuando éstos buscan afectar las políticas aplicadas en sus territorios. Los estudios que existen, sin embargo, apuntan a la importancia de la autonomía de estos actores sociales/civiles para relacionarse con el Estado y los actores armados y reducir los niveles de violencia o el escalamiento de la criminalidad. Moncada plantea que, en el caso de los empresarios, la autonomía de acceso a capital legal es importante para generar esta resistencia (2019: 326). Para otros autores es la historia de estas organizaciones (ej. organizaciones barriales, comunidades indígenas) las que les permite consolidarse en el territorio (Arias 2019; Ley et al. 2019; Lobo y Vélez 2020).

Los actores sociales construyen esta autonomía, incluso negociando los bordes de su propia legalidad (Dewey 2016) dado que la existencia de una economía 
ilegal en el territorio plantea múltiples formas directas e indirectas de vínculos a lo ilícito. El simple hecho de que el cultivo de coca sea una actividad prohibida por la ley, no significa que los agricultores de coca sean vistos como narcotraficantes por otros; debe tenerse en cuenta el proceso de calificación que la sociedad y el Estado hacen de este comportamiento (Becker 2009). Los agricultores cocaleros en los Andes han venido negociando su legalidad desde el inicio de la prohibición del cultivo de la hoja de coca, con resultados muy variados. Grisaffi (2019) señala que los agricultores del Chapare han logrado, a pesar de estar bastante vinculados a actividades ilícitas, defender su legitimidad como agricultores bajo el lema "coca sí, cocaína no". Algo similar ocurre en el VRAEM donde se considera narcotraficante a un grupo reducido de actores que no es equivalente a todos aquellos vinculados con la economía ilegal de la coca. Los "nachos" (narcotraficantes) son considerados intermediarios, no los agricultores, y estos tienen un nivel de ganancias más elevado en la cadena de valor ilegal (Vizcarra 2018). Estos bordes de legalidad son revalidados por el Estado reconociendo a estos actores como representantes legítimos de los territorios para la negociación.

Cómo influyen estos actores en la construcción de una política de tolerancia de la economía ilícita requiere considerar más que su autonomía. Las organizaciones sociales no cuentan con los mismos recursos materiales que los actores no estatales armados para contrarrestar o competir con el poder material del Estado (ej. militar, administrativo) cuando este quiere desplegar su poder sobre el territorio (Boone 2012; Eaton 2012). Sin embargo, a pesar de que los actores sociales no cuentan con estos recursos materiales, pueden apelar a los recursos políticos y simbólicos sobre los cuales se basa la presencia negociada del Estado en el territorio. El alcance territorial del Estado no sólo ocurre a través del despliegue de su capacidad militar o armada, sino también de un proceso de acumulación del capital político/simbólico en el territorio a través de la negociación con actores no estatales (Loveman 2005). El poder relativo de los actores sociales radica en esta forma negociada y relacional en la que el Estado extiende su alcance territorial (Giraudy y Luna 2017).

Así, la implementación heterogénea de la política nacional de erradicación de coca en el Perú, en particular, la política de tolerancia en el VRAEM no puede ser entendida sin analizar el tipo de desarrollo del Estado en el territorio y su "efecto" (Mitchell 1991: 94). La primitiva acumulación de capital político/ simbólico del Estado en el VRAEM es constitutivo de la pacificación del territorio y del control de los grupos subversivos a fines de los años 90s en el Perú. El Estado logra ordenar la vida social y pacificar el territorio restringiendo la violencia de actores insurgentes, pero no lo hace solo, sino con el soporte de las organizaciones de los agricultores y su economía ilícita de coca. Esto no ocurrió en otros valles como el Alto Huallaga, donde estos grupos lograron el relativo 
apoyo de la población. ${ }^{12}$ Una literatura creciente muestra que el alcance territorial en zonas ilícitas no solo ocurre, sino que se produce a través de procesos de estatalidad negociada (Meehan 2015: 278), donde el poder político/simbólico del Estado radica tanto en "actos de sumisión y de obediencia" de parte de los actores no estatales, como actos de "conocimiento y reconocimiento" por parte del Estado (Bourdieu 2000: 172), incluyendo la actividad ilegal misma.

En el VRAEM, los intentos de llevar adelante la erradicación, y la posible apertura de un conflicto abierto con los agricultores cocaleros, han planteado la amenaza de debilitar esta presencia y capacidad estatal lograda en el territorio, en convivencia con la economía ilícita (Heuser 2019). Este orden informal e híbrido ha mostrado su funcionalidad controlando la violencia y evitando la monopolización de la economía ilícita por actores no estatales armados. La amenaza de debilitar este orden en un contexto nacional ya de alta conflictividad en el país por otras causas como las industrias extractivas, ${ }^{13}$ planteamos ha llevado a la suspensión consecutiva de los intentos de erradicación en el VRAEM por parte de más de tres gobiernos.

Este argumento se resume en la Tabla 1, ubicando al VRAEM en comparación con otros valles productores de una manera referencial. Este artículo no hace una comparación sistemática de estos valles y tampoco de las consecuencias de la erradicación en los lugares donde se lleva a cabo. ${ }^{14}$ Queremos mostrar, sin embargo, el despliegue de diferentes dimensiones de la capacidad estatal de Mann, según las clasificaciones de Soifer (2012) en los valles cocaleros. Esto para explicar los resultados heterogéneos de la implementación de la política de erradicación a nivel subnacional. En particular, señalamos que la política de tolerancia en el VRAEM no puede ser explicada por la ausencia de capacidad coercitiva o administrativa del Estado (dimensiones I y II en la tabla 1$){ }_{r}^{15}$ las cuales según los indicadores disponibles existen y son similares en el VRAEM y en otros valles donde se implementa la política de erradicación. La dimensión III destaca la importancia de la capacidad política y relacional del Estado que se ha construido en el VRAEM, sobre la base de una alianza antisubversiva histórica entre agricultores cocalero y el Estado, en particular las Fuerzas Armadas durante el conflicto armado interno y donde el carácter simbólico de esta alianza cobra relevancia para los actores sociales y la mantención de un orden social híbrido en la zona. En otras zonas como Monzón-AH y el Corredor Amazónico, la relación con el Estado se ha caracterizado más bien por la criminalización de

12 Estos contrastes entre ambos valles se explicarán a mayor detalle en la sección 4.

13 Desde el inicio de los 2000, el crecimiento acelerado del Perú sobre la base del boom de commodities y en particular la expansión de la minería ha provocado un clima de alta conflictividad local en diferentes partes del territorio nacional (Paredes 2016)

14 Los pocos estudios, en realidad, indican que la erradicación suele enfrentar la resiembra (DIRANDRO 2020), impulsa el desplazamiento de los agricultores a otras zonas, ampliando la frontera cocalera, e incrementa las posibilidades de deforestación y la inseguridad en más partes del territorio nacional (Grillo 2018; Arriarán 2020)

15 No incluimos la dimensión extractiva del Estado que es la problemática en todos los casos por ser economías ilícitas donde la capacidad de regulación de las actividades económicas es débil o lo que está en disputa. 
las organizaciones cocaleras, que consiste en un discurso que asocia a los agricultores cocaleros con grupos subversivos y/o narcotraficantes.

Tabla 1. Despliegue de diferentes dimensiones de la Capacidad Estatal principales Valles Cocaleros

\begin{tabular}{|c|c|c|c|c|}
\hline \multirow[b]{2}{*}{$\begin{array}{c}\text { Zonas } \\
\text { productoras }\end{array}$} & \multicolumn{3}{|c|}{ Dimensiones de la Capacidad Estatal } & \multirow[b]{2}{*}{$\begin{array}{l}\text { Resultado: } \\
\text { erradicación } \\
{ }^{(4)}\end{array}$} \\
\hline & $\begin{array}{c}\text { I } \\
\text { Capacidad } \\
\text { de Coerción: } \\
\text { Militar, Policial, } \\
\text { de Acceso }^{(2)} \\
\end{array}$ & $\begin{array}{c}\text { II } \\
\text { Capacidad } \\
\text { Administrativa: } \\
\text { Distribución de } \\
\text { Servicios Públicos }{ }^{(3)} \\
\end{array}$ & $\begin{array}{c}\text { III } \\
\text { Capacidad } \\
\text { Política: } \\
\text { Relacional con los } \\
\text { Actores Sociales } \\
\end{array}$ & \\
\hline VRAEM & Muy Alta & Media & Negociación & Muy baja \\
\hline Monzón - AH & Alta & Media & Criminalización & Alta \\
\hline $\begin{array}{c}\text { Corredor } \\
\text { Amazónico } \\
\text { de la Selva } \\
\text { Central }\end{array}$ & Media & Media & Criminalización & Alta \\
\hline $\begin{array}{c}\text { Triple } \\
\text { Frontera }\end{array}$ & Baja & Media & Control & Media \\
\hline $\begin{array}{l}\text { San Gabán - } \\
\text { Inambari }\end{array}$ & Media & Media & Control & Media \\
\hline
\end{tabular}

(1) Valles delimitados por DEVIDA (2020); (2) Medida por el número de comisarías en la zona: tanto en el VRAEM como en el Monzón-AH existen 10 comisarías; en el Corredor Amazónico existen 16 comisarías; mientras que en la Triple Frontera existen 5 comisarías; y en San Gabán únicamente 2 (INEI 2017); (3) medida por la Densidad Estatal de PNUD (2019); (4) en base a los datos de CORAH (S.F) y DIRANDRO (2020).

\section{ACTORES SOCIALES Y LA SUSPENSIÓN DE LA ERRADICACIÓN EN EL VRAEM}

El objetivo de esta sección es mostrar cómo los actores sociales en el VRAEM han resistido la erradicación y logrado suspender los tres intentos de aplicar dicha política nacional durante los años 2000 - 2019. El VRAEM es una unidad territorial organizada por la economía ilegal de la coca cuyos límites cuentan con criterios poco claros. Sin embargo, como muestra el Gráfico 1, los gobiernos progresivamente han demarcado el espacio territorial para implementar sus políticas. La entidad responsable de la política de control de las drogas es la Comisión para el Desarrollo y Vida Sin Drogas (DEVIDA) que se apoya en el Proyecto Especial CORAH para planificar y ejecutar las acciones de erradicación. ${ }^{16}$

16 Programa Especial de Control y Reducción del Cultivo de la Coca en el Alto Huallaga (CORAH) creado en 1979 a cargo del Ministerio del Interior. Actualmente las campañas de erradicación se realizan con personal civil y resguardo policial armado en el marco de la Política Nacional de Drogas dirigida y supervisada por DEVIDA. 
Gráfico 1. Mapa del VRAEM

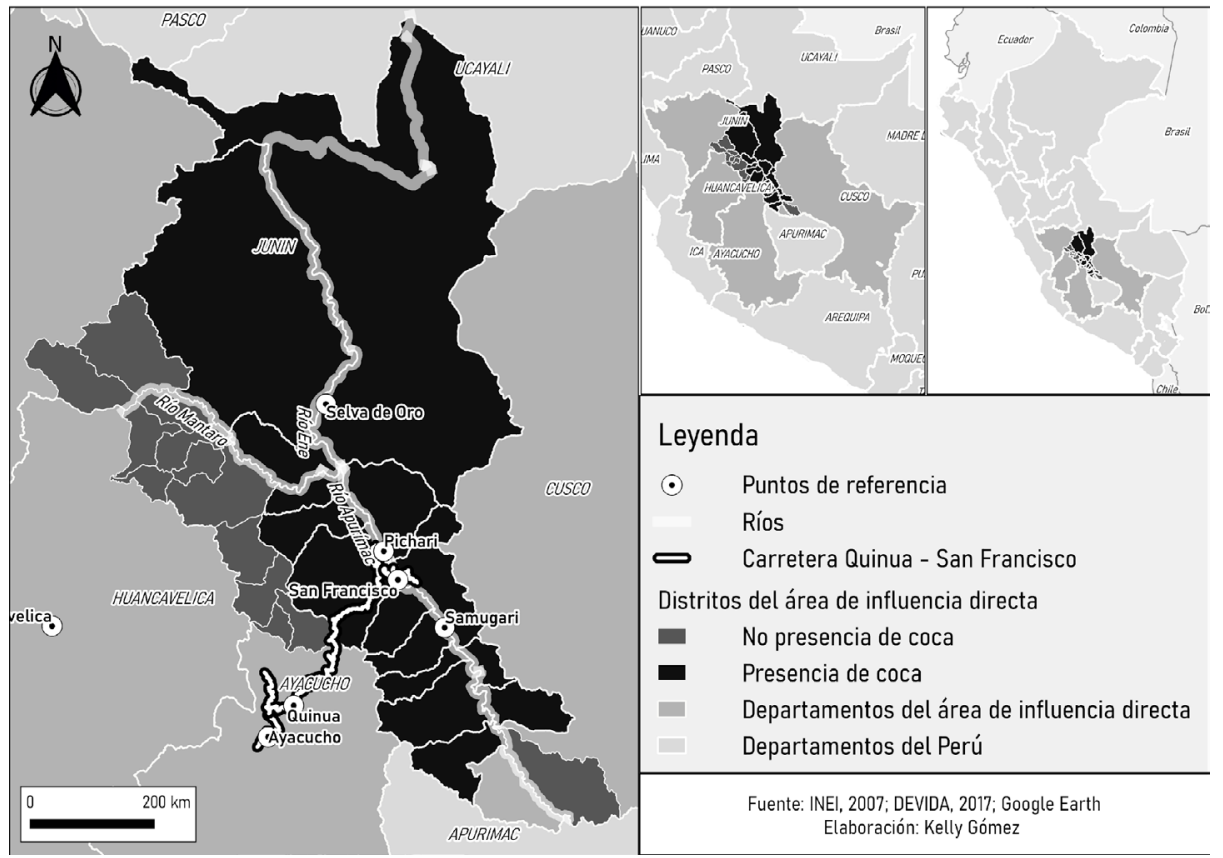

Desde el regreso a la democracia en el año 2001, sucesivos gobiernos han intentado una política de erradicación en el VRAEM motivados por la fuerte presión internacional de reducir la producción de coca. El Gráfico 2 organiza estos intentos que han sido respondidos por la Federación de Agricultores Agropecuarios del VRAE (FEPAVRAE) y los Comités de Autodefensa (CADs) dando lugar a lo que en este artículo se concibe como una política de tolerancia en la zona. 
Gráfico 2: Política Nacional de control de cultivos ilícitos y su resultante subnacional en el VRAEM (2000-2019)

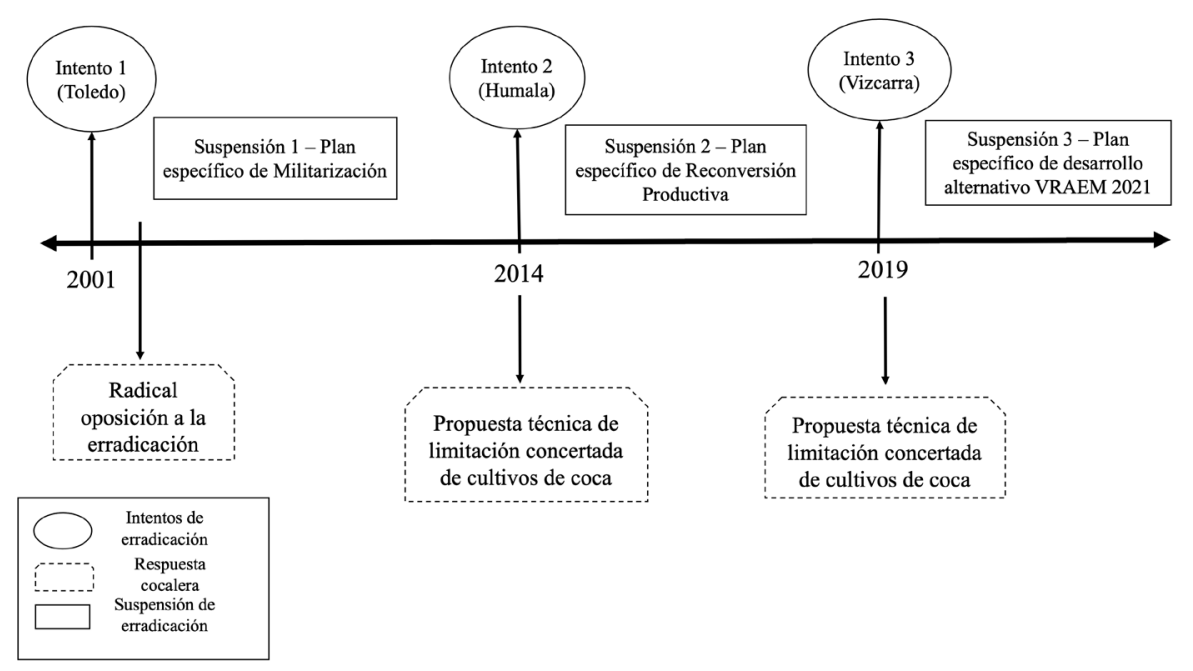

Fuente: Elaboración propia

\section{Política Coca Cero (Toledo 2001-2006)}

El gobierno de Alejandro Toledo tuvo que enfrentar el descontento social que se inició entre fines del gobierno de Fujimori y el gobierno transitorio de Paniagua por el reinicio de la política de erradicación de cultivos en los valles del norte del país, el Monzón -AH y en el Corredor de la Selva Central en Aguaytía. Inicialmente optó por continuar con las mesas de diálogo que se iniciaron en el gobierno de Paniagua con las organizaciones cocaleras (Durand-Ochoa 2014). Sin embargo, la posición del gobierno cambió radicalmente y anunció una política de 'coca cero' a nivel nacional debido a las presiones de Estados Unidos, que exigía resultados en la lucha contra las drogas para renovar el Tratado de Preferencias Arancelarias (ATPDEA) con el Perú en el año 2002 (Rojas 2005; Ponce 2016). Para llevar a cabo esta política, se constituyó DEVIDA, como la entidad adscrita a la Presidencia de Consejos de Ministros que se encargaría de coordinar el cumplimiento de los objetivos de dicha política, en donde se incluía las metas de hectáreas erradicadas de coca.

La FEPAVRAE lideró la protesta en la ciudad de Huamanga durante cuatro días en agosto de 2002 rechazando cualquier forma de erradicación en el país y exigiendo el diálogo directo con el presidente y / o el premier (Durand-Guevara 2009: 285-293). Esto generó entre el 2002 y el 2003 una breve articulación del movimiento cocalero nacional (Durand-Ochoa 2014). Se creó en el 2003 la Confederación Nacional de Productores Agropecuarios de las Cuencas Cocaleras del Perú (CONPACCP) que articuló a los agricultores cocaleros del Monzón- 
AH, Aguaytía en el Corredor de la Selva Central, y del VRAEM. El liderazgo de Nelson Palomino, dirigente de la FEPAVRAE, jugó un rol central en las protestas y en la radicalización del discurso de "coca o muerte."

La radicalización facilitó el rápido control de la protesta por parte del Estado con la detención de su líder Nelson Palomino en febrero del 2003 (Rojas 2005; Durand-Ochoa 2014), ${ }^{17}$ provocando el colapso y la división de la CONPACCP. Los agricultores del VRAEM rechazaron la firma del acuerdo de Alejandro Toledo (Decreto Supremo 044-2003) con las otras bases cocaleras para establecer una erradicación gradual y concertada de los cultivos de coca. La FEPAVRAE se desafilió de la CONPACCP y mantuvo un discurso de "coca o muerte." Las organizaciones de los otros valles se fragmentaron posteriormente debido a que los líderes perdieron legitimidad frente a sus bases porque los acuerdos con el gobierno no fueron cumplidos y la erradicación continuó siendo impuesta en la práctica en las áreas del Monzón -AH y Aguaytía, del Corredor de la Selva Central, con un promedio de 8000 hectáreas anuales (Durand-Ochoa 2014).

Paradójicamente, a pesar de la radicalización y debilitamiento de la FEPAVRAE, el gobierno suspendió la erradicación forzosa en el VRAEM. Algunos ex funcionarios e investigadores han señalado que existía una sensación en el gobierno central de que el "fantasma del terrorismo" se reactivará en la zona recientemente pacificada (Basombrío y Rospligiosi 2006: 129; Durand-Ochoa 2014: 68), por lo que envía una comisión de alto nivel a Huamanga para negociar una política específica (Rojas 2005).

\section{La emulación del "modelo Alto Huallaga-Monzón" (Humala 2011-2016)}

Ollanta Humala ofreció en su campaña electoral del 2012 la prohibición de la erradicación forzosa. Sin embargo, muy temprano en su gobierno, dio un giro en la dirección de sus políticas macroeconómicas, en general, y de control de drogas, en particular (Koven y McClintock 2018). DEVIDA planteó la erradicación del valle del Monzón-AH y extender la erradicación en el Corredor de la Selva Central a Pichis-Palcazú (Grillo 2018). A pesar de la erradicación en estos valles en el 2012, con 24 mil hectáreas erradicadas en total, el Perú pasó a ser el primer productor de coca ilegal en el $2012 .{ }^{18}$ Estas cifras, y el ánimo de emular el éxito en el Monzón-AH en el VRAEM, llevaron al Estado, en particular DEVIDA, con apoyo del CORAH, a proponer como meta alcanzar las 30000 hectáreas erradicadas anuales para el año 2014 y eso implicaba la erradicación en el VRAEM.

17 Palomino fue detenido por la toma de una estación de radio opositora a la FEPAVRAE en Pichari como parte de la protesta de la organización.

18 En el 2012 los cultivos en el Perú se estimaron en 60400 hectáreas, superando a Colombia (47788 hectáreas) y Bolivia (25300 hectáreas) (UNODC 2014) 
El anuncio de erradicación en el VRAEM provocó la protesta de la FEPAVRAE en Pichari, esta vez con un discurso menos radical y orientado a una propuesta técnica de reducción gradual y concertada de la coca sin "procesos de erradicación que solo generarían derramamiento de sangre, caos."19 Ante la intensificación de las protestas, el gobierno suspendió la erradicación por segunda vez e instauró una mesa de diálogo entre la FEPAVRAE, y las agencias estatales DEVIDA, el CORAH, la FFAA, la Policía Antidrogas, el Ministerio de Agricultura, los gobiernos locales y el gobierno regional de Ayacucho. El 27 de mayo en la ciudad de Huamanga estos actores acordaron una reducción paulatina de los cultivos de coca a través del programa de reconversión productiva (con otorgación de bonos) a cargo del Ministerio de Agricultura, no de DEVIDA, sin erradicación compulsiva por parte del CORAH. También, se estableció reforzar la presencia de las Fuerzas Militares con apoyo policial, para interdicción de drogas y captura de terroristas (MINAGRI 2016; Vizcarra y Hueser 2019). Nuevamente, de acuerdo a nuestras entrevistas ${ }^{20}$ e investigaciones previas (Holmes 2015: 43; Koven y McClintock 2018: 65; Zevallos y Casas 2019), fueron las fuerzas militares quienes consideraban que la erradicación sería contraproducente para mantener la pacificación en el VRAEM, la cual estaba a su cargo.

\section{6 hectáreas erradicadas (Vizcarra 2018-2020)}

El 28 de julio del 2019, el presidente de la República anunció que, en dicho año, el CORAH iniciaría las acciones de erradicación en el VRAEM. El argumento central tanto de DEVIDA como del Ministerio del Interior era que las Comunidades Asháninkas que se encuentran en la zona del VRAEM solicitaban la erradicación de los cultivos en su territorio. Esta versión fue cuestionada luego por miembros de comunidades Asháninkas visitados en nuestro trabajo de campo en la zona, quienes sostienen que sus bases sociales no fueron consultadas para el ingreso del CORAH a sus territorios y que hay muchos líderes indígenas que alquilan sus terrenos para cultivo de coca voluntariamente.

Ante ello, la FEPAVRAE convocó a una serie de paros y marchas en Pichari donde se exigía, nuevamente, la instalación de mesas de diálogo con altos funcionarios del gobierno. En medio de una gran tensión en octubre 2019, en la mesa de diálogo de Pichari, junto con el Premier y los líderes cocaleros, se acordó que la erradicación se llevaría a cabo solamente en la zona de Alto Anapati (Mazamari) a solicitud de las comunidades nativas y fuera de la jurisdicción de la FEPAVRAE - identificada con 15 distritos. Sin embargo, cuando se llevó a cabo la erradicación de 116 hectáreas en noviembre, los agricultores cocaleros señalan que se realizó en un territorio no reconocido como parte de las Comu-

19 Documento proporcionado en el Trabajo de Campo 2020 (FEPAVRAE. 8 de febrero de 2014. Propuesta Técnica de la FEPAVRAE). Entrevista a ex Secretario Técnico de la FEPAVRAE 17.02.20.

20 Entrevista con Coronel(r) del VRAEM 5.04.20; Entrevista a ex funcionario del CORAH 27.11.19; Entrevista a ex funcionario MINAGRI 14.11.19. 
nidades Ashaninkas. Además, sostienen que erradicaron algunas hectáreas en la zona Nueva Esperanza y Campo Verde (Pangoa), que forma parte de los distritos de la FEPAVRAE. ${ }^{21}$ Todas estas quejas y el desarrollo progresivo de protestas hicieron rápidamente retroceder al gobierno de Vizcarra y dejar la erradicación en el VRAEM por tercera vez suspendida.

Los agricultores cocaleros organizados en la FEPAVRAE y sus Comités de Defensa CADs han sido capaces de frenar la erradicación desplegando recursos de movilización colectiva - paros, protestas, elaboración de propuestas técnicas, poder de convocatoria a ciudadanos, y capacidad para negociar con autoridades de nivel central. Esta capacidad de negociación se ha diferenciado de otras organizaciones cocaleras en otros valles, como en el Monzón-AH donde el Estado ha podido ampliar su política de erradicación. Las dirigencias de la FEPAVRAE no han estado libres de tensiones y contradicciones internas, tal como ha indicado Durand-Ochoa (2014); sin embargo, en momentos en que existen amenazas de erradicación, la movilización social viene acompañada de una apelación al rol simbólico de los agricultores y la economía cocalera en la pacificación local del territorio y la posibilidad del desarrollo estatal en el VRAEM.

\section{EL ORÍGEN DE LA ALIANZA EN TORNO A LA PACIFICACIÓN DEL TERRITORIO}

En esta sección explicamos empíricamente cómo se origina el poder simbólico de la pacificación en el VRAEM y la tolerancia a la economía de la coca en este proceso. El crecimiento del VRAEM como productor de coca ilícita se ha dado progresivamente con las políticas de colonización promovidas en los 60s (Aramburú 1982; Bedoya-Garland 2016) y luego con el impulso del mercado global de cocaína en los 70s (Gootenberg 2008: 307). Sin embargo, a inicios de los 80s se inician las primeras conexiones con el mercado internacional de cocaína (Vizcarra 2018: 89), el principal productor en el Perú en esa década era el AH (Gootenberg 2008). A finales de los ochenta, el AH alcanzó una producción de 145000 hectáreas de coca (Cotler 1999: 119), mientras que en el VRAEM entre 1988 y 1994 se estima que existieron 30000 hectáreas (UNODC 2002).

En la década de los ochenta, los contrastes y secuencias entre el VRAEM y el $\mathrm{AH}$ son claves para entender las diferencias. La alta producción de coca en el Alto Huallaga atrajo a los grupos subversivos como Sendero Luminoso (SL) y el Movimiento Revolucionario Túpac Amaru (MRTA) que aparecieron en los ochenta para aprovechar la economía ilegal. Estos grupos intentaron monopolizar esta economía y se aliaron con los agricultores para defender los cultivos de las políticas de erradicación (CVR 2003; Felbab-Brown 2010; van Dun 2012). En el VRAEM, SL no llegó atraído por la economía de la coca que era aún muy 
incipiente en comparación con el AH. Llegó replegándose del conflicto armado con las FFAA en la sierra ayacuchana (CVR 2003: 440).

Con el conflicto armado en su mayor auge en Ayacucho, los agricultores en el VRAEM crecieron en número también. Se ubicaron fundamentalmente en la margen derecha del valle en los distritos de Kimbiri y Pichari (mirar Gráfico 1). ${ }^{22}$ Estos agricultores, que venían al VRAEM huyendo de la violencia del conflicto, vieron como una amenaza la presencia de SL, organizándose en su contra. Esta defensa se volvió más dura por la violencia ejercida por SL y, posteriormente, por los militares hacia los líderes agricultores. En este contexto se crearon los "muntuneros" cuyo objetivo principal era luchar contra SL (CVR 2003: 440). ${ }^{23}$ Mientras que en el AH no se crearon organizaciones de autodefensa ante la violencia armada durante el conflicto (CVR 2003: 391; van Dun 2012: 445), los "muntuneros" que luego se oficializaron como Comités de Autodefensas (CAD's) por el gobierno de Fujimori, se enfrentaron a SL apoyándose crecientemente en los ingresos de la coca para comprar armas y mantener a las cuadrillas de vigilancia (del Pino 1996; CVR 2003). Esto evitó que los actores subversivos monopolizaran la economía de la coca como ocurrió en el AH. Con el avance del conflicto armado interno, las CADs recibieron el apoyo de las fuerzas armadas quien les entregó armas y los reconoció como "pacificadores de la nación" (Cotler 1999; McClintock \& Vallas 2005). No es que la relación de CADSs con las fuerzas armadas no haya sido de tensión durante este periodo, pero al mismo tiempo, éstas últimas reconocieron progresivamente que las CADs eran actores clave en la lucha antisubversiva en la zona.

En el momento más violento del conflicto armado, entre 1989 - 1995, el gobierno de Fujimori decidió suspender la erradicación pese a la presión norteamericana. La evaluación del gobierno era que el enemigo principal eran los grupos subversivos (Cotler 1999; McClintock \& Vallas 2005) y que la política de erradicación hacía más difícil la lucha contra estos grupos, principalmente en el AH, por el soporte que tenían de parte de los agricultores y narcotraficantes (Felbab-Brown 2010; Manrique, 2017). En el VRAEM, la coca no era aún vista como un grave problema por sus limitadas dimensiones y porque los agricultores se oponían a SL. El coronel Víctor, un ex mando militar que entrevistamos, señaló que en el VRAEM la erradicación ya había sido desestimada por las fuerzas armadas como "una cuestión de sobrevivencia", y que el narcotráfico era una "cosa secundaria."

La lucha por la pacificación en alianza con las CADs fue una lucha efectiva. Mientras que las acciones senderistas disminuían, la tolerancia hacia la producción de coca ilícita por parte de los militares y el gobierno contribuyó a que el cultivo de coca se convierta en la principal actividad económica del territorio

22 La población de ambos distritos aumentó de 14570 habitantes en el año 1983 a 40518 habitantes en 1991 (CVR 2003: 87)

23 Organización de vigilantismo cuyo objetivo es el uso colectivo o amenaza de la violencia extralegal en respuesta a un presunto acto criminal (Moncada 2017). 
a mediados de 1990 (del Pino 1996: 127-128; Heuser 2019: 27). ${ }^{24}$ Con el regreso a la democracia y la pacificación de la zona, los CADs fueron perdiendo importancia pública, pero se convirtieron en la principal base organizativa del movimiento cocalero en el VRAEM, la FEPAVRAE. ${ }^{25}$ En el Monzón-AH, por el contrario, los agricultores de coca y sus organizaciones siempre han sido sospechosos de sus vínculos con los grupos subversivos (van Dun 2012). El mejor ejemplo de esto es la detención de varios líderes de las organizaciones cocaleras del Monzón por su supuesta vinculación al Camarada Artemio de SL durante la intervención en dicha zona (Casas y Ramírez 2017).

La pacificación del VRAEM en la década del 2000 no fue equivalente a la eliminación total de SL. Hubo remanentes que se replegaron a la zona del Vizcatán del Ene, un espacio boscoso de muy difícil acceso. Desde allí ejecutaron algunas emboscadas a las fuerzas del orden, e impusieron cuotas al "libre tránsito" a los mochileros traficantes que se desplazan por el Vizcatán (Holmes 2015; Taylor 2017) ${ }^{26}$ Sin embargo, este repliegue ha permitido la concentración de las fuerzas armadas que han capturado durante esta década a la mayor parte de sus líderes, quedando una reducida facción, quien según información de prensa busca negociar su amnistía. Los mismos medios señalan que, según fuentes militares, estos grupos se encuentran desmoralizados, sufriendo enfermedades que no pueden atender en la zona. ${ }^{27}$ En efecto, en un comunicado reciente, el Ministerio de Defensa informó que uno de los más importante líderes de esta facción de SL, Jorge Quispe Palomino, el 'camarada Raúl', falleció a causa de una enfermedad renal. ${ }^{28}$

La alianza de los agricultores cocaleros con el Estado para la pacificación del VRAEM guarda fuertes contrastes con el AH, y en particular el área del Monzón. La autonomía de estas organizaciones de los actores subversivos ha hecho más difícil su criminalización por parte de los actores del Estado, que buscan avanzar en la erradicación. Además, se han creado organizaciones de defensa como las CADs que colaboraban con el cuidado del orden social, y esta pacificación ha permitido el incremento de la presencia estatal a través de oficinas administrativas y de servicios, bases militares y policiales del Estado en la zona (Vizcarra y Heuser 2019). En la siguiente sección mostraremos cómo se experimentó el último intento de erradicación en el VRAEM, y cómo las organizaciones hacen esta apelación a su participación, y la economía de la coca, en la pacificación del territorio.

\footnotetext{
Entrevista ex Secretario Técnico de FEPAVRAE 17.02.20.

Entrevista a dirigente cocalero de la FEPAVRAE 17.02.20

Ver: IDL (2012)

Desde el año 2012, el Comando Especial VRAEM y las Brigadas Especiales ha logrado capturar a varios líderes terroristas, entre los más importantes los camaradas Alipio y Gabriel en el 2013 (IDL 2013). Actualmente, la facción de SL es liderada por Víctor Quispe Palomino, camarada "José". Respecto a su situación actual e intentos de pedir amnistía ver el reportaje de Meza (2019). 


\section{APELANDO AL PODER DE LA PACIFICACIÓN Y LA POLÍTICA DE LA TOLERANCIA}

Cuando empezamos nuestra investigación, el presidente Vizcarra anunció en julio de 2019 el tercer intento de erradicación en el VRAEM. En el territorio, encontramos una situación de mucho movimiento, reuniones y mucha disposición a hablar e invitarnos a sus asambleas. Paul y Jorge, dirigentes de la FEPAVRAE, estaban yendo a una 'bajada de base', una asamblea a unos 40 minutos de Pichari. En el camino, nos dijo que nació y se crió en el VRAEM y que durante el conflicto armado interno "era normal ver muertos tirados en el río" y que "no se podía pasar así no más" como ahora hacíamos. Resaltó que esto fue así hasta que "se organizaron los muntuneros y botaron a los tíos", como llaman actualmente a los miembros de SL. Fueron 30 minutos hablando de cómo creció admirando el trabajo de defensa de las CADs contra SL.

Al llegar el centro poblado, nos recibe un joven con un arma larga y vieja, y tiene un polo negro que dice "Comité de Autodefensa". Había alrededor de 100 agricultores hombres y mujeres en la asamblea, y un grupo de 8 adultos y jóvenes armados con viejos fusiles. Nos dijeron que estas armas las adquirieron del ejército, y que algunas fueron compradas durante el conflicto armado interno con plata de la coca.

Nuestra percepción es que estuvimos frente a una escenificación (Goffman 1959) para nosotros, pero también para las fuerzas militares y policiales que nos dijeron que siempre pueden tener sus infiltrados en las reuniones. El líder de los CADs mandó a "ponerse firmes", izar la bandera nacional y cantar el himno del Perú antes de iniciar la asamblea, rito militar adoptado por estas organizaciones. Ya en la discusión, un dirigente recalcó: "nosotros hemos pacificado el VRAE, a nosotros nos debe [el Estado] la pacificación y la lucha frontal contra el terrorismo, ni un muerto más en esta zona a costa de que el gobierno en su intención cojuda quiere meter erradicación acá, ni un muerto más. Creo que hemos dado nuestras vidas, muchas familias han muerto, hemos comprado armamento, cuando nosotros hemos enfrentado con el terrorismo hemos comprado con la economía coca, armamento, rancho, todo lo demás y lo hemos enfrentado y lo hemos pacificado nosotros. Por eso compañeros, ni un muerto más." ${ }^{29}$ En la asamblea hubo varias otras intervenciones reivindicando la economía ilícita de la coca en la lucha contra SL. En otra asamblea volvimos a escuchar a uno de los participantes señalar algo muy similar, "la hoja de coca ha jugado un papel muy importante [en la pacificación] ¿Dónde comité de autodefensa, dónde ha adquirido el armamento? a través de la cosecha de coca, mi comunidad, cosechando, hemos adquirido tres armas de larga distancia, con eso hemos defendido [el valle]." ${ }^{\prime 30}$

Para los agricultores cocaleros el rol de sus organizaciones en la pacificación del territorio no es solo pasado. Un CAD de Pichari señala que su colaboración 
con las fuerzas militares y policiales es clave para "brindar seguridad y orden", con una serie de riesgos, "nos meten bala, podemos morir y no hay nada [salario, seguro de salud]. Ese es el problema, nosotros sin embargo seguimos trabajando en bienestar del Estado." ${ }^{31}$ Un dirigente cocalero manifestó que "han empezado a matar gente, creo que es ajuste de cuentas, pero, estas cosas pasan selectivamente, o sea, no es un descontrol, en el VRAEM, ¿dónde? Lo que tú vas a ver en cada comunidad es un Comité de Autodefensa con sus sacos, con su arma, con su escopeta. Entonces, esa es la autoridad, entonces tampoco permitiremos que una banda de narcotraficantes tome por asalto a un pueblo y que hagan lo que les venga en gana, no, no, no. Entonces, eso acá no ha ido a más por este tema del contrato, por todo el historial que tiene." ${ }^{\prime 32}$

El VRAEM no es un lugar con altos índices de violencia letal como otros lugares donde operan economías ilegales. Sin embargo, a medida que uno se aleja de Pichari, el centro urbano, y se acerca a los centros poblados más remotos podemos observar, al ingreso de estos centros poblados, sacos de arena con al menos un hombre con arma y 'chicote' en mano. ${ }^{33}$ Los CADs pidieron nuestros nombres y documento de identidad para entrar a algunas comunidades, el cual nos fue devuelto al finalizar nuestra visita. Poggi (2005: 144) plantea que la pacificación del territorio por parte de Estado no significa necesariamente la desaparición de la violencia potencial, menos en un territorio de alta economía ilegal como el VRAEM, sino el control de su ejercicio real, o de que la amenaza de esta violencia disminuya debido al funcionamiento de un orden de control.

Este rol de vigilancia a nivel local permite a los CADs colaborar efectivamente con las fuerzas policiales y armadas. La conexión entre las fuerzas del orden y los miembros de los CADs es frecuente. El Ejército recluta principalmente en la zona, así los jóvenes que luego se vuelven miembros de las CADs cuentan con entrenamiento y una cultura militar. El Autodefensa señaló la importancia de ayudar a las fuerzas estatales "porque, digo la verdad, la Policía Nacional, por decir, hay un asalto en Pampa Hermosa, ellos no salen al toque, tienen que dar parte a su jefe, a su superior, al general, ellos autorizan, ${ }^{\prime 34}$ haciéndonos entender que ellos intervienen primero.

En nuestras visitas pudimos observar como la amenaza de la erradicación reactiva la apelación simbólica a su participación en la pacificación. Un líder nos señalaba "cuidado que el comité de autodefensa puede reaccionar contra el Estado, contra las fuerzas policiales y fuerzas militares. Lo decimos sutilmente, pero eso es lo que yo converso con mucha gente: 'Yo soy autodefensa, yo soy activo. Tengo mi arma que nos ha dado el gobierno. Y si es que van a mi chacra, yo voy a disparar." ${ }^{\prime 35}$ Además, plantean que las fuerzas armadas y policiales son incapaces de mantener la seguridad y el orden en el VRAEM solos, "Si la autodefensa se desactiva, el VRAEM

\footnotetext{
Entrevista a miembro del Comité de Autodefensa Pichari. 9.12.19. Entrevista a dirigente cocalero de la FEPAVRAE. 17.02.20.

Palo de madera que usan para "poner orden" a las personas que incumplen las normas locales (Nota de Campo 8.12.2019)

34 Entrevista a miembro del Comité de Autodefensa Pichari. 9.12.19.

35 Entrevista ex Secretario Técnico de FEPAVRAE 17.02.20.
} 
va a ser tierra de nadie, por qué, porque hay crimen organizado, con armas largas están, y eso saben muy bien las autoridades, la policía, todos saben. Entonces, la autodefensa de nosotros, hasta el momento, hacemos respetar, con nuestra arma que tenemos." ${ }^{36}$

En cada periodo en el que se ha buscado la erradicación en el VRAEM se han reactivados efectivamente estas apelaciones. En conjunto con la movilización, estas apelaciones, han logrado suspender la erradicación en un contexto estatal donde los diferentes actores miran con diferentes prioridades la política de erradicación. Como hemos señalado antes, en el Estado pueden convivir varios "proyectos estatales" que compiten entre sí (Auyero y Sobering 2019: 12). En el Perú hay actores que más claramente buscan cumplir con sus metas nacionales de erradicación como DEVIDA y el CORAH; mientras que otros, como las fuerzas militares, encargadas de la tarea de la pacificación, tienden a considerar con mayor preocupación las consecuencias de la erradicación en el VRAEM.

La anécdota de un Coronel(r) con larga actividad en el VRAEM gráfica bien esto: "el año pasado, el Ministro de Defensa fue a inaugurar una franja ahí en Pichari, ahí un aeródromo, una franja y dijo en su discurso 'este gobierno va a pacificar el VRAEM.' Al día siguiente me llama un amigo agricultor, y me dice, como contándome la historia, 'mi coronel, ayer ha venido el Ministro de Defensa, ha dicho que va a pacificar el VRAEM..., pero, pero si acá estamos en paz.'” El coronel reflexiona y continúa, "¿cuál es la amenaza ahora en el VRAEM? Ninguna, más bien los que amenazamos somos la fuerza del orden, con esos anuncios [] despiertan los muertos vivientes [SL y discursos radicales] []. Para la población el narcotráfico es una forma de vida, tal vez no para el Estado, pero para la población sí, hay que entender eso." 37

\section{CONCLUSIONES}

Este artículo busca explicar la heterogeneidad del alcance territorial del Estado en la erradicación de cultivos ilícitos de coca en el Perú, en particular la política de tolerancia en el VRAEM. Plantea que no solo la capacidad unilateral del Estado es importante (ej. su fuerza militar, administrativa), sino la capacidad relacional, en particular en contextos de actividad ilegales. Los actores no estatales imponen importante resistencia a las políticas nacionales de los Estados. Planteamos que los actores sociales son actores no estatales, que en contextos de actividad ilícita han sido menos estudiados porque se los ha visto como más débiles en contexto de alta violencia. Sin embargo, estos actores sociales como lo mostramos en este artículo son actores que se relacionan con el Estado de formas complejas, ya que pueden experimentar múltiples vinculaciones directas e indirectas a las economías ilegales, pero también pueden negociar los bordes de su legalidad con el Estado y la sociedad en general. Los agricultores cocaleros han hecho esto desde la prohibición de los cultivos de coca, con diferentes resultados, no solo nacionales, sino subnacionales, como mostramos en este artículo. 
La creciente literatura del Estado en zonas de ilegalidad enfatiza que la capacidad de alcance de los Estado es frecuentemente negociada con actores armados no estatales, el cual muchas veces debe hacer coaliciones para gestionar, en lugar de monopolizar los medios de coerción. En estos casos, la violencia política y las economías ilegales se encuentran fuertemente vinculadas. Sin embargo, ambas dinámicas son diferentes y pueden configurar diferentes formas de relación entre los Estados y los actores vinculados a economías ilegales, como el caso peruano plantea: los Estados pueden aliarse (o tolerar) a los actores vinculados a las economías ilegales para privilegiar el control de la violencia política, mientras estos actores colaboren en garantizar la pacificación y un relativo orden social. La forma en cómo los actores sociales se vinculan a estos procesos emprendidos por el Estado, y sus desafiantes políticos, parece clave para entender su rol en el futuro en socavar los planes futuros de centralización del Estado, en particular de reducir las economías ilícitas.

La literatura de colusión de los actores estatales e ilegales nos permiten entender mejor la acción e inacción del Estado respecto a las economías ilícitas, el acomodamiento de los actores estatales a estas economías cuando éstas pueden viabilizar el desarrollo del propio Estado, o incluso de los políticos mismos. Encontramos que nuestros resultados dialogan con estudios de la minería informal del oro que señalan que, por ejemplo, en zonas de Bolivia, el Estado ha buscado un acomodamiento con los actores sociales vinculados a esta economía para viabilizar el desarrollo del Estado en un momento de boom de precios que podía atraer actores desestabilizantes del orden social, como ocurrió en otros contextos, ej. Perú y Colombia (Baraybar y Dargent 2020). O el análisis más reciente de Holland (2017), que plantea que el cumplimiento de la ley no solo responde a la capacidad del Estado de sancionar, sino también de si políticamente elige hacerlo.

Para finalizar es importante mencionar que la "suspensión" de la erradicación, no es solución. Y que el carácter temporal de estas negociaciones expresa las asimetrías entre los agricultores y el Estado, con implicaciones para los pobladores y su futuro. La suspensión de la ley y las negociaciones descritas implican relaciones de poder asimétricas que otorga a los agentes del gobierno central el control del "suspenso", o de la espera, diría Javier Auyero (2012). Los agricultores experimentan la incertidumbre sobre cuándo y por qué el Estado decidirá intentar aplicar la erradicación otra vez, y esperan una salida negociada (hasta ahora no permitida) para practicar el cultivo de coca bajo un orden menos informal, precario y amenazante.

\section{REFERENCIAS}

Aramburú, Carlos Eduardo. 1982. "La Expansión de la Frontera Agraria y Demográfica en la Selva Alta Peruana." En Colonización en la Amazonía, editado por Carlos Aramburú. Lima: CIPA, 1-39. 
Arce, Moisés y Leonardo Reales. 2006. “Violencia Política, Asistencia Militar de Estados Unidos y Producción de Coca en los Andes Centrales." Revista de Ciencia Política 26(1): 25-47.

Arias, Enrique Desmond. 2019. "Social Responses to Criminal Governance in Rio de Janeiro, Belo Horizonte, Kingston, and Medellin." Latin American Research Review 54(1): 165-80.

Arias, Enrique Desmond. 2017. Criminal Enterprises and Governance in Latin America and the Caribbean. Cambridge: Cambridge University Press.

Arjona, Ana. 2017. "Civilian Cooperation and Non-Cooperation with Non-State Armed Groups: The Centrality of Obedience and Resistance." Small Wars and Insurgencies 28(4-5): 755-78.

Arriarán, Gabriel. 2020. Un Mapeo de Actores. La Trata y la Corrupción en el Contexto del Narcotráfico y la Pandemia del COVID-19 en el Trapecio Amazónico. Lima: PROETICA.

Auyero, Javier. 2012. Patients of the State: The Politics of Waiting in Argentina. Durham: Duke University Press.

Auyero, Javier y Katherine Sobering. 2019. The Ambivalent State. Police-Criminal Collusion at the Urban Margins. Oxford: Oxford University Press.

Ballvé, Teo. 2012. "Everyday State Formation: Territory, Decentralization, and the Narco Landgrab in Colombia." Environment and Planning D: Society and Space 30(4): 603-22.

Baraybar, Viviana y Eduardo Dargent. 2020. "State Responses to the Gold Rush in the Andes (2004-2018): The Politics of State Action (and Inaction)" Studies in Comparative International Development 55: 516-537

Basombrío, Carlos y Fernando Rospigliosi. 2006. La Seguridad y sus Instituciones en El Perú a Inicios del Siglo XXI: Reformas Democráticas o Neomilitarismo. Lima: IEP.

Bedoya-Garland, Eduardo. 2016. "La Deforestación y la Tragedia de los Comunes entre los Cocaleros del VRAE: 2001-2004." Espacio y Desarrollo 101(28): 75-101.

Becker, Howard. 2009. Outsiders: Hacia una Sociología de la Desviación. Buenos Aires: Siglo XXI.

Boone, Catherine. 2012. "Territorial Politics and the Reach of the State: Unevenness by Design." Revista de Ciencia Política 32(3): 623-41.

Bourdieu, Pierre. 2000. Pascalian Meditations. Stanford: Stanford University Press.

Bourdieu, Pierre. 2014. On the State. Lectures at the College de France, 1989-1992. Cambridge: Polity Press.

Buxton, Julia. 2015. "Drugs and Development: The Great Disconnect." Policy Report 2. Global Drug Policy Observatory, Swansea.

Casas, Frank, y Mariana Ramírez. 2017. “Actores y Escenarios como Determinantes Clave de la Política de Drogas en Perú. El Caso de la Implementación del Control de Hoja de Coca en el Valle del Monzón (2010-2015)." Revista de Ciencia Política y Gobierno 4(7): 33-57.

CORAH. (S.F). Estadísticas - CORAH. Recuperado el 7 de mayo de 2020 de https://mail. corahperu.org/.

Cotler, Julio. 1999. Drogas y Política en el Perú. La Conexión Norteamericana. Lima: IEP.

CVR. 2003. Informe Final. Lima: CVR.

Dargent, Eduardo, Andreas E. Feldmann, y Juan Pablo Luna. 2017. “Greater State Capacity, Lesser Stateness: Lessons from the Peruvian Commodity Boom." Politics and Society 45(1):3-34.

Dávalos, Eleonora. 2016. "New Answers to an Old Problem: Social Investment and Coca Crops in Colombia." International Journal of Drug Policy 31:121-30.

del Pino, Ponciao. 1996. "Tiempos de Guerra y de Dioses: Ronderos, Evangélicos y Senderistas en el valle del río Apurímac." En Las rondas campesinas y la derrota de Sendero Luminoso, editado por Iván Degregori et al. Lima: IEP, 117-188.

DEVIDA. 2017. Estrategia Nacional de Lucha Contra las Drogas. Lima: DEVIDA.

DEVIDA. 2020. Política Nacional Contra las Drogas al 2030. Lima: PCM.

DEVIDA. (S.F). Indicadores de Política: Rendimiento de superficie cultivada con arbusto de hoja de coca. Recuperado el 20 de marzo del 2020 de https:/ / sistemas.devida.gob.pe/siscod/ indicadores 
Dewey, Matías. 2015. El Orden Clandestino. Política, Fuerzas de Seguridad y Mercados Ilegales en la Argentina. Buenos Aires: Katz Editores

Dewey, Matías. 2016. "Porous Border: The Study of Illegal Markets from a Sociological Perspective." Documento de Trabajo, No. 16/2, MPIfG, Cologne.

Dewey, Matías. 2018. "Zona Liberada. La Suspensión de la Ley como Patrón de Comportamiento Estatal." Revista Nueva Sociedad (276): 102-117.

DIRANDRO. 2020. Tendencias de las Redes Criminales del Tráfico Ilícito de Drogas. Lima: DIRANDRO.

Duran-Martinez, Angelica. 2015. “To Kill and Tell? State Power, Criminal Competition, and Drug Violence." Journal of Conflict Resolution 59(8): 1377-1402.

Durand-Guevara, Anahí. 2009. "Aquí están los Cocaleros: un Acercamiento a las Protestas Cocaleras en el Valle del Río Apurímac." En Entre el Crecimiento Económico y la Insatisfacción Social. Las Protestas Sociales en el Perú Actual, editado por Romeo Grompone y Martín Tanaka. Lima: IEP, 264-319.

Durand-Ochoa, Ursula. 2014. The Political Empowerment of the Cocaleros of Bolivia and Peru. New York: Palgrave Mcmillan.

Eaton, Kent. 2012. "The State of the State in Latin America: Challenges, Challengers, Responses and Deficits." Revista de Ciencia Política 32(3): 643-57.

El Peruano. 2021, 3 de marzo. Fuerzas Armadas Confirman Muerte de Jorge Quispe Palomino "Camarada Raúl." Recuperado el 30 de marzo de 2021 de https:/ / elperuano.pe/ noticia/117901-fuerzas-armadas-confirman-muerte-de-jorge-quispe-palomino-camarada-raul

Felbab-Brown, Vanda. 2010. Shooting Up: Counterinsurgency and the War on Drugs. Washington, D.C: Brookings Institution Press.

Giraudy, Agustina, Eduardo Moncada y Richard Snyder, eds. 2019. Inside Countries: Subnational Research in Comparative Politics. Cambridge: Cambridge University Press.

Giraudy, Agustina y Juan Pablo, Luna. 2017. "Unpacking the state's uneven territorial reach: Evidence from Latin America." En States in the Developing World, editado por Miguel Centeno, Atul Kohil y Deborah Yashar. Cambrigde: Cambrigde University Press, 93-120.

Grillo, Luciana. 2018. “Coca, Café y Cacao: Lucha Contra las Drogas y Estrategias de Vida en Agricultores del Valle del Monzón." Debates En Sociología (47): 101-130.

Grisaffi, Thomas. 2019. Coca Yes, Cocaine No. How Bolivia's Coca Growers Reshaped Democracy. Durham: Duke University Press.

Goffman, Erving. 1959. La Presentación de la Persona en la Vida Cotidiana. Buenos Aires: Amorrortu.

Gootenberg, Paul. 2008. Andean Cocaine: The Making of a Global Drug. Chapel Hill: The University of North Carolina Press.

Heuser, Christoph. 2019. "The Effect of Illicit Economies in the Margins of the State - The VRAEM." Journal of Illicit Economies and Development 1(1): 23-36.

Holmes, Jennifer S. 2015. "Sendero Luminoso After Fujimori: A Sub-National Analysis." The Latin Americanist 59(2): 29-50.

Holland, Alisha. 2017. Forbearance as redistribution: The politics of informal welfare in Latin America. Cambridge: Cambridge University Press.

IDL. 2012, 16 de julio. "Sendero Luminoso y el Narcotráfico en el VRAE." Recuperado el 6 de enero de 2020 de https:/ / www.idl-reporteros.pe/sendero-luminoso-y-el-narcotrafico-en-el-vrae/

IDL. 2013, 13 de agosto. “Cómo cayó Alipio." Recuperado el 6 de enero de 2020 de https:/ / www.idl-reporteros.pe/como-cayo-\%E2\%80\%98alipio\%E2\%80\%99/

INEI. 2017. Perú: IV Censo Nacional de Comisarías 2017. Lima: INEI

INEI. 2020. Perú: Estimaciones y Proyecciones de Población por Departamento, Provincia y Distrito, 2018-2020. Lima: INEI

Janoski, Thomas. 2019. "Toward the Convergence of Culture and Political Economy?: Pierre Bourdieu, Michael Mann, and Institutional Theory." En The New Handbook of Political 
Sociology, editado por Thomas Janoski, Cedric de Leon, Joya Misra e Isaac Martin. Cambridge: Cambridge University Press, 216-242

Keefer, Philip y Norman Loayza. 2010. Innocent Bystanders: Developing Countries and the War on Drugs. Washington, D.C: Palgrave Mcmillan.

Koven, Barnett y Cynthia McClintock. 2018. "Violence in Peru." En Violence in the Americas, editado por Hanna Kassab y Jonathan Rosen. London: Lexington Books, 47-70.

Lapegna, Pablo. 2009. "Ethnographers of the World....United? Current Debates on the Ethnographic Study of Globalization." Journal of World-Systems Research XV (1): 3- 24.

Ley, Sandra, Shannan Mattiace, y Guillermo Trejo. 2019. “Indigenous Resistance to Criminal Governance: Why Regional Ethnic Autonomy Institutions Protect Communities from Narco Rule in Mexico." Latin American Research Review 54(1): 181- 200.

Lobo, Ivan, and María Alejandra Vélez. 2020. "From Strong Leadership to Active Community Engagement: Effective Resistance to Illicit Economies in Afro Colombian Collective Territories." Documento de Trabajo No 3, CESED, Bogotá.

Loveman, Mara. 2005. "The Modern State and the Primitive Accumulation of Symbolic Power." American Journal of Sociology 110(6): 1651-83.

McClintock, Cynthia y Fabián Vallas. 2005. La Democracia Negociada: Las Relaciones Perú - Estados Unidos (1980 - 2000). Lima: IEP.

Mann, Michael. 1986. The Sources of Social Power. Cambridge: Cambridge University Press.

Mansfield, David. 2016. A State Built on Sand. How Opium Undermined Afghanistan. Oxford: Oxford University Press.

Manrique, Hernán. 2017. "El Largo Camino hacia la Economía Lícita: Estado y Estrategias de Desarrollo Alternativo en el "Milagro de San Martín»." Revista de Ciencia Política y Gobierno 4(7): 161-89.

Meehan, Patrick. 2015. "Fortifying or Fragmenting the State? The Political Economy of the Opium/Heroin Trade in Shan State, Myanmar, 1988-2013." Critical Asian Studies 47(2): 253-82.

Meza, Junior. 2019, 10 mayo. "Enfermedades Atacan a Altos Mandos y Personas en Cautiverio de Sendero Luminoso en el VRAEM." Recuperado el 6 de julio de 2019 de https: / / ojo-publico.com/1264/Somos-conscientes-de-matanzas-de-Sendero-en-Vraem-esono-puede-quedar-impune.

Migdal, Joel. 2001. State in Society. Studying How States and Societies Transform and Constitute One Another. Cambridge: Cambridge University Press

MINAGRI. 2016. Un Enfoque Sostenible en el VRAEM. Lima: MINAGRI.

Mitchell, Timothy. 1991. "The Limits of the State: Beyond Statist Approaches and Their Critics." The American Political Science Review 85(1): 77-96.

MEF. S. F. Consulta Amigable. Recuperado el 26 de febrero de 2021 de https: / /apps5.mineco. gob.pe/transparencia/Navegador/default.aspx?y=2019\&ap=ActProy.

INEI. 2007. Censos Nacionales 2007: XI de Población y VI de Vivienda. Lima: INEI.

INEI. 2020. Perú: Estimaciones y Proyecciones de Población por Departamento, Provincia y Distrito, 2018-2020. Lima: INEI

Moncada, Eduardo. 2017. "Varieties of Vigilantism: Conceptual Discord, Meaning and Strategies." Global Crime 18(4): 403-23.

Moncada, Eduardo. 2019. "Resisting Protection: Rackets, Resistance, and State Building." Comparative Politics 4(1): 321-39

Moriconi, Marcelo, y Carlos Aníbal Peris. 2019. "Merging Legality with Illegality in Paraguay: The Cluster of Order in Pedro Juan Caballero." Third World Quarterly 40(12): 2210-27.

Paredes, Maritza. 2016. "The glocalization of mining conflict: Cases from Peru." Extractive Industries and Society 3(4): 1046-1057

PNUD. 2019. Perú: El reto de la igualdad. Lima: PNUD.

Poggi, Gianfranco. 2005. "Political Power Un-manned: A Defence of the Holy Trinity from Mann's Military Attack." En An Anatomy of Power. The Social Theory of Michael Mann, editado por John Hall y Ralph Schroeder. Cambridge: Cambridge University Press, 135-149. 
Ponce, Aldo. 2016. "From Freedom to Repression and Violence: The Evolution of Drug Policy in Peru." En Drug Policies and the Politics of Drugs in the Americas, editado por Beatriz Labate et al. Suiza: Springer, 123-148.

Ramírez, María. 2001. Entre el Estado y la Guerrilla: Identidad y Ciudadanía en el Movimiento de los Campesinos Cocaleros del Putumayo. Bogotá: ICANH

Rogowski, Steve. 2010. Social Work: The Rise and Fall of a Profession. Bristol: Policy Press.

Rojas, Isaías. 2005. "Peru: Drug Control Policy, Human Rights and Democracy." En Drugs and Democracy in Latin America: The Impact of U.S. Policy, editado por Youngers Coletta y Rosin Eileen. Lynne Rienner Publishers, 182-230.

Rosen, Jonathan y Hanna Samir Kassab. 2019. Drugs, Gangs and Violence. Cham: Palgrave Mcmillan

Rouse, Stella y Moises Arce. 2006. "The Drug-Laden Balloon: U.S. Military Assistance and Coca Production in the Central Andes." Social Science Quarterly 87(3):540-57.

Soifer, Hillel. 2012. "Measuring State Capacity in Contemporary Latin America." Revista de Ciencia Política 32(3): 585-598.

Taylor, Lewis. 2017. "Sendero Luminoso in the New Millennium: Comrades, Cocaine and Counter-Insurgency on the Peruvian Frontier." Journal of Agrarian Change 17(1): 106-21.

Thoumi, Francisco. 2010. "Competitive Advantages in the Production and Trafficking of Coca-Cocaine and Opium-Heroin in Afghanistan and the Andean Countries." En Innocent bystanders: Developing Countries and The War on Drugs, editado por Phillip Keefer y Norman Loayzs. Washington, D.C: Palgrave Mcmillan and The World Bank, 192-252.

Trejo, Guillermo, y Sandra Ley. 2020. Votes, Drugs and Violence. The Political Logic of Criminal Wars in Mexico. Cambridge: Cambridge University Press

UNODC. 2002. Perú: Monitoreo de Cultivos de Coca 2001. Lima: UNODC.

UNODC. 2014. Perú: Monitoreo de Cultivos de Coca 2013. Lima: UNODC.

UNODC. 2018. Perú: Monitoreo de Cultivos de Coca 2017. Lima: UNODC.

van Dun, Mirella. 2012. "The Drugs Industry and Peasant Self-Defence in a Peruvian Cocaine Enclave." International Journal of Drug Policy 23(6): 442-448.

Vizcarra, Sofía. 2018. "La Economía Moral de la Ilegalidad en la Ciudad Cocalera: Significados y Prácticas Legitimadoras del Narcotráfico en la Ciudad de Pichari (2000-2017)." Tesis doctoral. Lima: Pontificia Universidad Católica del Perú.

Vizcarra, Sofía y Christoph Heuser. 2019. “Los Estados en los Márgenes: Soberanía y Gubernamentalidad en el Principal Valle Cocalero Peruano." Sociologias 21(52): 164-90.

Youngers, Coletta y Eileen Rosin. 2005. Drugs and Democracy in Latin America: The Impact of U.S. Policy. Colorado: Lynne Rienner Publishers.

Zevallos, Nicolás y Frank Casas. 2019. “Una Lectura de las Capacidades Estatales desde las Resistencias a la Erradicación de Hoja de Coca en un Valle Cocalero del Perú" Gestión y Política Pública 28(2): 473-500.

Recibido: 4 de agosto de 2020

Aceptado: 14 de marzo de 2021

Maritza Paredes. Es Profesora Asociada de Sociología del Departamento de Ciencias Sociales de la Pontificia Universidad Católica del Perú. Directora del Doctorado en Sociología. Doctora en Desarrollo Internacional por la Universidad de Oxford y Magíster en Políticas Públicas por la Universidad de Columbia. Investiga y publica sobre conflictos ambientales, la política del cambio climático, los impactos de las industrias extractivas, las economías ilegales y la política de los pueblos indígenas. Correo electrónico: maritza.paredes@pucp.pe

Álvaro Pastor. Es Asistente de docencia del Departamento de Ciencias Sociales y de Investigación en el Centro de Investigaciones Sociológicas, Económicas, Políticas y Antropológicas (CISEPA) de la Pontificia Universidad Católica del Perú. Licenciado en Sociología por la Pontificia Universidad Católica del Perú (PUCP). Asistente de Investigación del Proyecto Regional Applicability of Innovative crop control Policy in the Andes ejecutado por el CISEPA-PUCP. Correo electrónico: alvaro.pastor@pucp.edu.pe 